\title{
Results from in vitro and ex vivo skin aging models assessing the antiglycation and anti-elastase MMP-I 2 potential of glycylglycine oleamide
}

This article was published in the following Dove Press journal:

Clinical, Cosmetic and Investigational Dermatology

22 June 2016

Number of times this article has been viewed

\author{
Patrick Bogdanowicz \\ Marie-José Haure \\ Isabelle Ceruti \\ Sandrine Bessou-Touya \\ Nathalie Castex-Rizzi \\ Department of Pharmacology, Pierre \\ Fabre Dermo-Cosmétique, \\ Toulouse, France
}

Background: Glycation is an aging reaction of naturally occurring sugars with dermal proteins. Type I collagen and elastin are most affected by glycation during intrinsic chronological aging. Aim: To study the in vitro and ex vivo assays in human skin cells and explants and the antiaging effects of glycylglycine oleamide (GGO).

Materials and methods: The antiglycation effect of GGO was assessed in a noncellular in vitro study on collagen and, ex vivo, by immunohistochemical staining on human skin explants (elastin network glycation). The ability of GGO to contract fibroblasts was assessed in a functional assay, and its anti-elastase (MMP-12) activity was compared to that of oleic acid alone, glycylglycine (GG) alone, and oleic acid associated with GG.

Results: In vitro, GGO reduced the glycation of type I collagen. Ex vivo, GGO restored the expression of fibrillin-1 inhibited by glycation. Furthermore, GGO induced a tissue retraction of almost $30 \%$. Moreover, the MMP-12 activity was inhibited by up to $60 \%$.

Conclusion: Under the present in vitro and ex vivo conditions, GGO prevents glycation of the major structural proteins of the dermis, helping to reduce the risk of rigidification. By maintaining the elastic function of the skin, GGO may be a promising sparring partner for other topical antiaging agents.

Keywords: extracellular matrix, glycylglycine oleamide, glycation, fibrillin-1, matrix metalloproteinase-12, skin aging

\section{Introduction}

Aging results from two processes: genetically encoded changes in an organism and modifications caused by a negative external environmental impact. The most visible signs of aging are those of the skin. ${ }^{1,2}$ In 2001, Chung et al investigated the modulation of skin collagen metabolism in aged and photoaged human skin. The authors concluded that the natural aging process decreases collagen synthesis and increases the expression of matrix metalloproteinases (MMPs). ${ }^{3}$

Dermal fibroblasts are a dynamic and diverse population of cells, which function in the skin including the turnover of the dermal matrix. They play an important role in cutaneous wound repair and an ever-increasing role in the bioengineering of the skin. ${ }^{4-7}$ Moreover, they are capable of producing collagen fibers, the main component of the extracellular matrix (ECM) of the dermal connective tissue. Simultaneously, fibroblasts connected to the collagen network provide dermal support for the epidermis and give rise to the elastic properties of a tissue..$^{4,8}$ In the skin, cell-ECM interactions influence normal homeostasis, aging, wound healing, and diseases. ${ }^{9}$
Correspondence: Patrick Bogdanowicz Department of Pharmacology, Pierre Fabre Dermo-Cosmétique, Avenue Hubert Curien - BP I3562, 31035

Toulouse Cedex I, France

Tel +33534506437

Fax +33534503433

Email patrick.bogdanowicz@pierre-fabre. com 
Elastic fibers are designed to maintain the elastic function for a lifetime. However, various enzymes such as MMPs and serine proteases are able to cleave elastic fiber molecules. ${ }^{10,11}$ Such loss of elasticity due to the degradation and rigidification of elastic fibers is a major contributing factor in aging of connective tissues. ${ }^{12-14}$ Indeed, while early stages of photoaging of the skin are characterized by the differential degradation of elastic fiber proteins, the activity of ECM proteases is increased in photoexposed skin. ${ }^{15}$

Fibrillins, including fibrillin-1, are components of the ECM and are often associated with elastin. Research has shown that fibrillin-1 can be used as a robust biomarker for repair of photoaged dermis. ${ }^{1}$

Glycation is an aging reaction of naturally occurring sugars with dermal proteins. The natural suppleness of the dermis is affected by the formation of bridges between proteins and sugars, named Maillard's reaction. ${ }^{16,17}$ Both adducts are susceptible to oxidation. The resulting aldehydes are called Amadori products or advanced glycation end products (AGEs). They are many times more reactive in altering proteins than glucose although only present in minute quantities. ${ }^{16-19}$ In recent years, the role of AGEs has been increasingly discussed in skin aging. ${ }^{19}$ Glycation-associated skin autofluorescence was shown to correlate with chronological aging in a large number of healthy subjects. ${ }^{20}$ Today, it is a general perception that AGE accumulation is dependent on protein turnover rates. Therefore, long-lived proteins such as type I collagen or elastin are thought to suffer from glycation during intrinsic chronological aging. ${ }^{21}$

The use of antiglycation agents in topical antiaging products has gained favor with cosmetic companies over the last years. ${ }^{22}$ Hence, developing new and powerful antiglycation agents is considered a new challenge for enlarging the spectrum of products limiting the negative impact of AGEs. Currently, different antiglycating agents are known such as extracts of blueberries, quercetin, silymarin, cloves, ginger, cinnamon, amino guanidine (aminoG), a reference inhibitor of glycation, glycylglycine (GG), urea, taurine, and carnosine. Among these, some limit the rigidification of collagen and elastin fibers in acting as a decoy for glucose, a molecule which is central to the process of dermal protein glycation. ${ }^{22-25}$

In this study, we provide results from different in vitro and ex vivo tests assessing the potential of a new small amphilic lipopeptide, glycylglycine oleamide (GGO), that is able to inhibit the glycation reactions and MMP-12 elastase activity.

\section{Materials and methods}

In the following studies, GGO was tested at different concentrations, allowing no direct comparison of the results between the different studies. The reason for these variations resides in the fact that the same concentration may be cytotoxic, depending on the study design. Therefore, for each study, the less cytotoxic concentration was chosen. French regulations (authorization is given the French Ministry of Research [Decree n ${ }^{\circ} 2007-1220$ ]) do not require ethical committee approval for the sampling of organ tissues for use in research studies.

\section{Noncellular in vitro testing of the anticollagen glycation potential of GGO}

For this in vitro study, the protocol developed by Brownlee et $\mathrm{al}^{26}$ was followed. Collagen was extracted from tissues obtained from esthetic surgery of patients who had provided donor consent prior to intervention. Collagen glycation was assessed by measuring the specific fluorescence of collagen-bound AGEs at $370 \mathrm{~nm}$ excitation $/ 450 \mathrm{~nm}$ emission. Type I collagen lattices were incubated for 4 hours with glycolaldehyde (GA; $50 \mathrm{mM}$ ), a strong glycation inducer, either alone or in the presence of the test molecules. The GGO solvent dimethyl sulfoxide served as a negative control, and aminoG at $250 \mathrm{mM}$ added to a GAtreated sample served as a positive control. Increasing concentrations of GGO (1 mM, $10 \mathrm{mM}$, and $50 \mathrm{mM})$ were added to the GA-treated sample to test for the molecule's antiglycation capacity. After incubation, mixtures were rinsed extensively with Dulbecco's phosphate-buffered saline. They were then analyzed for fluorescence with a spectrometer using $370 \mathrm{~nm}$ excitation/450 nm emission to estimate the quantity of AGEs.

The experiment was conducted once; the different results obtained were each the mean of six wells.

\section{Ex vivo immunohistology of human skin explants to assess the potential of GGO for restoring the number of fibrillin-I immunoreactive fibers}

Human skin explants from two different donors, having provided their written donor consent, were cultured at $37^{\circ} \mathrm{C}$ and a $\mathrm{CO}_{2}$ pressure of $5 \%$ in a standard cell culture medium; no details about its composition were provided by the supplier. Such prepared explants were incubated or not with methylglyoxal at $500 \mu \mathrm{M}$ for 8 days to induce glycation. ${ }^{17}$ Certain samples were concomitantly treated with GGO at $10 \mu \mathrm{M}$. After incubation, samples were frozen at $-80^{\circ} \mathrm{C}$. Tissue slides of $5 \mu \mathrm{m}$ were cut using a cryostat and stained with Bouin. Fibrillin-1 was detected by incubating tissue sections with monoclonal antibodies (1/200, clone 11.C1.3; Neo markers Inc. [Fremont, CA, USA]). Immunostaining on a Masson trichrome counterstained tissue and visualization of fibrillin-1 was performed using the streptavidine/peroxidase method (R.T.U.VECTASTAIN ${ }^{\circledR}$ Universal $^{\circledR}$ 
ABC Kit Vector Laboratories, Inc., CA, USA). Nuclei were stained using propidium iodide.

No primary antibody was added for controlling the nonspecific labeling (data not shown).

\section{Collagen retraction assay to assess the functioning of fibroblast contractility}

In a functional assay inspired by the experiments published by Bell et al, ${ }^{27}$ the collagen retraction potential of GGO was assessed in collagen gels with a baseline surface of $19.6 \mathrm{~cm}^{2}$. Fibroblasts were obtained from skin explants from subjects undergoing esthetic procedures and having provided written donor consent. Cultured fibroblasts were treated with $8 \mu \mathrm{M}$, $25 \mu \mathrm{M}, 76 \mu \mathrm{M}$, or $252 \mu \mathrm{M}$ GGO. The crude collagen solution at $3 \mathrm{mg} / \mathrm{mL}$ was provided by the Institut de Biotechnologies Jacques Boy, France. Protein lattices containing $4 \times 10^{5}$ fibroblasts were prepared in bacteriological dishes containing Dulbecco's Modified Essential Medium and fetal calf serum (FCS $5 \%$ or $1 \%$; Thermo Fisher Scientific, Waltham, MA, USA). FCS 5\% served as an internal positive control (booster of retraction), while FCS $1 \%$ served as an internal negative control. The concentrations of GGO used corresponded to noncytotoxic and nonproliferative assets. Three batches were set: batch no 1 (FCS 1\%), batch no 2 (FCS 5\%), and batch no 3 (GGO at $8 \mu \mathrm{M}, 25 \mu \mathrm{M}, 76 \mu \mathrm{M}$, or $252 \mu \mathrm{M}$ and FCS $1 \%$ ). Overall, six collagen lattices by batch were prepared. Two hours after incubation, gels were detached from the dishes' border and bottom, and the evolution of retraction over time was quantified by measuring the diameter of two axes of each lattice. Regular lattice measurements up to 160 hours were performed to assess dermal contraction. One single experiment was performed; results were the mean of the six gels. The surface was measured six times at six different areas. The decrease in the average diameter of the two axes was used for statistical analyses and was termed contraction.

The tissue surface $\left(\mathrm{mm}^{2}\right)$ was determined using the following calculation:

$$
\frac{\Pi \times d 1 \times d 2}{4}
$$

where $d$ is the diameter.

The $\%$ retraction was calculated based on the initial surface using the following calculation:

$$
\frac{19.6-\text { surface of the treated sample } \times 100}{19.6}
$$

The statistical analysis was performed using Microsoft Excel $^{\circledR}$ (Microsoft Corporation, Redmond, WA, USA). Results were expressed in percent changes and in mean \pm SD $\left(\mathrm{cm}^{2}\right)$ and were shown for the most pertinent period ranging from T0 up to T23.

\section{In vitro testing of the anti-elastase (MMP-I2) potential of GGO}

The anti-elastase activity of GGO $2.5 \mathrm{mM}$ was compared to that of oleic acid (OA) $2.5 \mathrm{mM}$, GG $2.5 \mathrm{mM}$, and a combination of OA $2.5 \mathrm{mM}$ and GG $2.5 \mathrm{mM}$. The method used was an in vitro noncellular technique described by Ashe and Zimmerman. ${ }^{28}$ This method is based on the diffusion of elastase in an agarose gel containing insoluble elastin stained with orcein and dispersed in the gel with or without the active ingredient. Orcein-stained elastin was prepared in the buffer solution Tris- $\mathrm{HCl} 0.02 \mathrm{M}$ at a $\mathrm{pH}$ of 8.2. A total of $1 \mathrm{~mL}$ of this solution was added to each well on a 24-well plate with each well having a surface area of $1.9 \mathrm{~cm}^{2}$. Each condition corresponded to the mean of four wells. In a hole of a diameter of $\sim 4 \mathrm{~mm}\left(0.13 \mathrm{~mm}^{2}\right)$ prepared using punch biopsy, $40 \mathrm{~mL}$ of a solution containing pancreatic elastase (3.7 units/mg; Sigma Aldrich Co., St Louis, MO, USA) at $25 \mu \mathrm{g} / \mathrm{mL}$ was added. The prepared wells were incubated at $37^{\circ} \mathrm{C}$ at a $\mathrm{CO}_{2}$ pressure of $5 \%$ and in a humid atmosphere. Reading of the lyses diameter after 48 hours of incubation allowed calculating the inhibition expressed in percent of the enzyme by the active ingredient according to the following formula:

$$
\frac{(\text { Treated surface }- \text { control surface }) \times 100}{(\text { Control surface }-0.13)}
$$

\section{Results \\ Noncellular in vitro testing of the anti-type I collagen glycation potential of GGO}

Collagen glycation was assessed by measuring the specific fluorescence of collagen-bound AGEs at $370 \mathrm{~nm}$ excitation $/ 450 \mathrm{~nm}$ emission.

A dose-dependent antiglycation effect of GGO after 24 hours of in vitro glycation of the collagen lattices was observed. This effect was proportional to the glycation rate. The positive reference product aminoG $250 \mathrm{mM}$ completely inhibited (100\%) the glycation process. When added to the collagen lattices, GGO $10 \mathrm{mM}$ inhibited the glycation process by $53 \%$ and by $59 \%$ when added at a concentration of $50 \mathrm{mM}$. Results presented in Figure 1 show a dose-dependent antiglycation potential of GGO. 


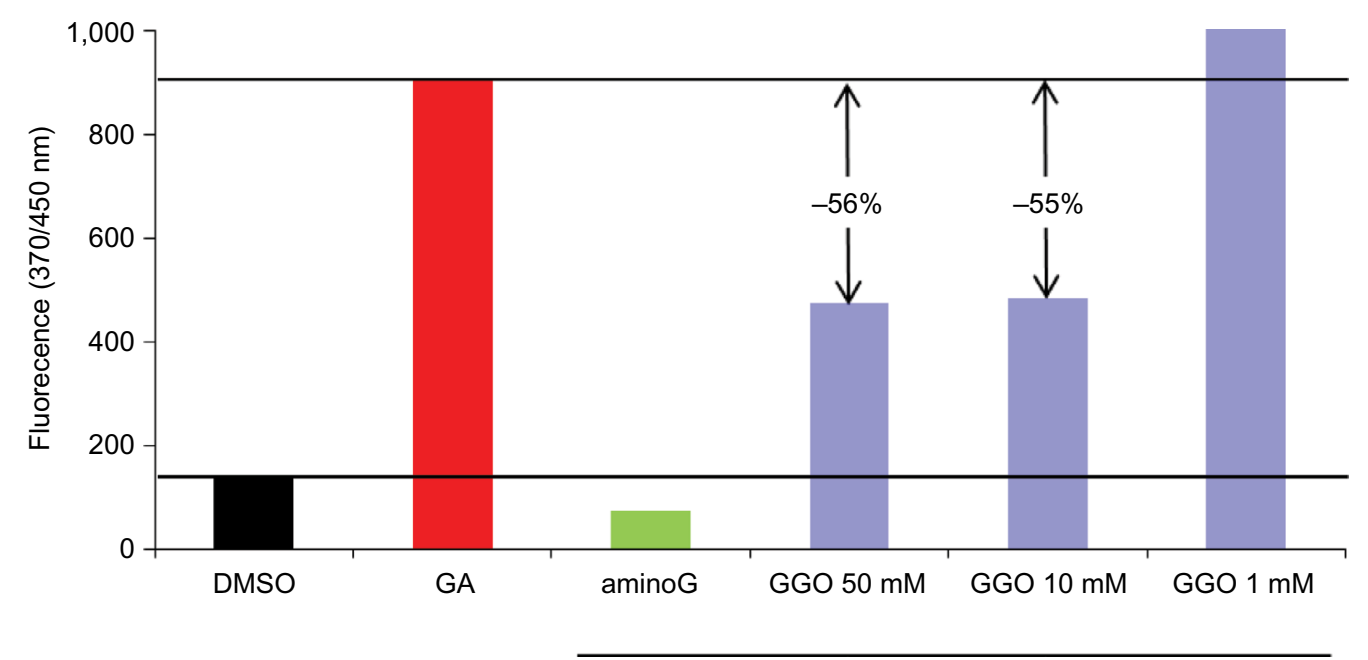

Figure I Noncellular in vitro testing of the anti-type I collagen glycation potential of GGO.

Notes: Collagen glycation was assessed using a fluorescence assay on collagen fibrils.

Abbreviations: GGO, glycylglycine oleamide; DMSO, dimethyl sulfoxide; aminoG: amino guanidine; GA, glycolaldehyde (50 mM).

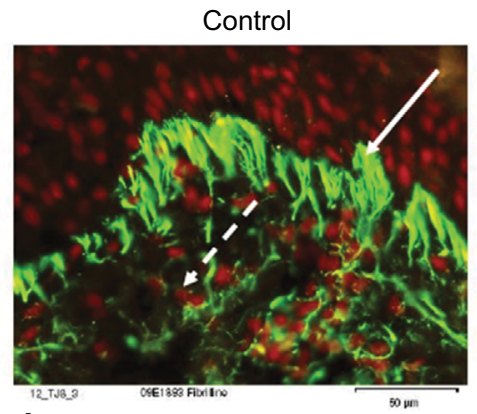

A

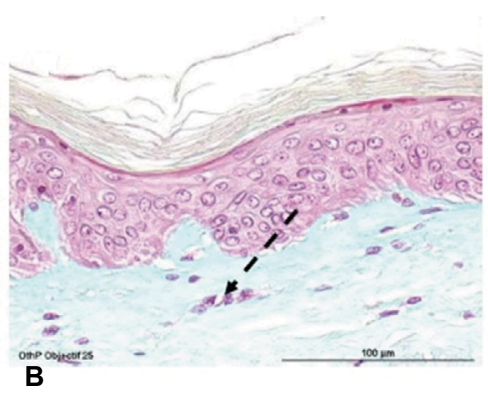

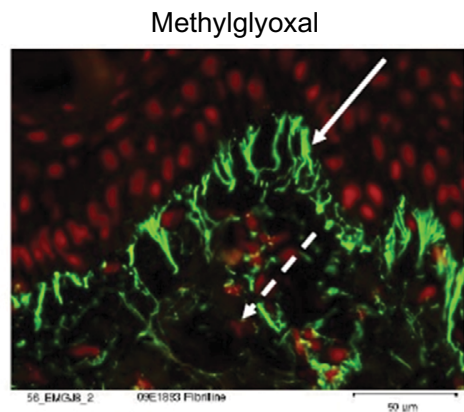

C

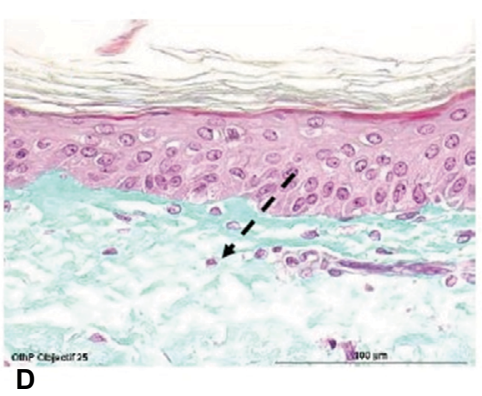

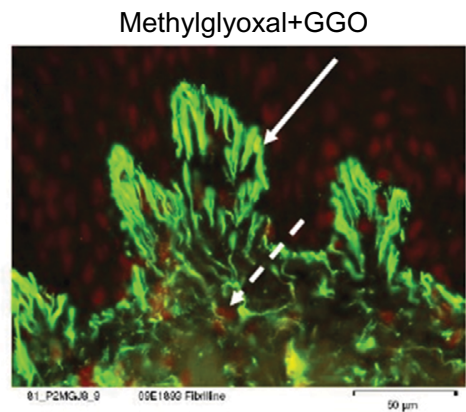

E

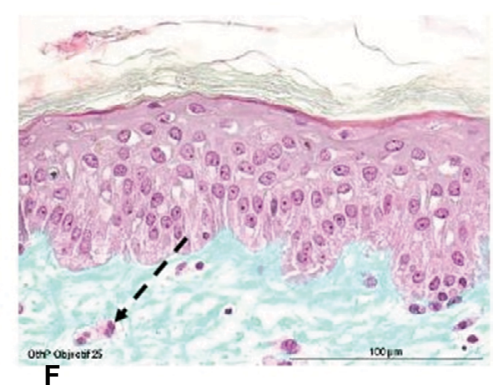

Figure 2 Ex vivo immunohistology of human skin explants assessing the potential of GGO for restoring the number of fibrillin-I immunoreactive fibers.

Notes: Human skin explants were cultured at $37^{\circ} \mathrm{C}$ and at a $\mathrm{CO}_{2}$ pressure of $5 \%$ in a standard cell culture medium and incubated or not with methylglyoxal at $500 \mu \mathrm{M}$ for 8 days to induce glycation. Certain samples were concomitantly treated with GGO at $10 \mu \mathrm{M}$. Dashed arrows show fibroblasts, solid arrows show fibrillin-I fibers. Fibrillin-I was detected by incubating tissue sections with monoclonal antibodies. Immunostaining on a Masson trichrome counterstained tissue and visualization of fibrillin-I were performed using the streptavidine/peroxidase method (A, C, and E). Nuclei were stained using propidium iodide. Tissue slides of $5 \mu \mathrm{m}$ were stained with Bouin (B, D, and F). Abbreviation: GGO, glycylglycine oleamide.

\section{Ex vivo immunohistology of human skin explants to assess the potential of GGO for restoring the number of fibrillin-I immunoreactive fibers}

Human skin explants were cultured at $37^{\circ} \mathrm{C}$ and at a $\mathrm{CO}_{2}$ pressure of $5 \%$ in a standard cell culture medium and incubated or not with methylglyoxal at $500 \mu \mathrm{M}$ for 8 days to induce glycation. Certain samples were concomitantly treated with GGO at $10 \mu \mathrm{M}$.

Figures $2 \mathrm{~A}$ and $2 \mathrm{~B}$ show untreated control samples. Methylglyoxal- induced glycation decreased the number of fibrillin-1 immunoreactive fibers (Figures 2C and 2D). The visible fibrillin-1 fibers were shortened and thinned (Figure 2C). When adding GGO $10 \mu \mathrm{M}$, the number of 
fibrillin-1 immunoreactive fibers was restored (Figure 2E). Although the overall morphology of the skin remained unchanged (Figures 2B, 2D, and 2F).

\section{Collagen retraction assay to assess the collagen retraction potential of GGO}

The collagen retraction potential of GGO was assessed in collagen gels with a baseline surface of $19 \mathrm{~cm}^{2}$. Cultured fibroblasts from skin explants were treated with GGO at $8 \mu \mathrm{M}, 25 \mu \mathrm{M}, 76 \mu \mathrm{M}$, or $252 \mu \mathrm{M}$.

The assay showed that GGO at $8 \mu \mathrm{M}, 25 \mu \mathrm{M}, 76 \mu \mathrm{M}$, and $252 \mu \mathrm{M}$ considerably increased the retraction of collagen gel: 23 hours after incubation, retraction was the less important with $7 \%$ for FCS $1 \%$. Retraction with GGO at $252 \mu \mathrm{M}$ was almost $30 \%$, and at a dose of $8 \mu \mathrm{M}, \mathrm{GGO}$ resulted in a retraction of almost $23 \%$, showing dose dependency. As expected, retraction was the most important with the internal positive control FCS 5\% (40\%). Results are shown in Figure 3.

After 23 hours, all tested concentrations of GGO had considerably increased the retraction of collagen gels
(Table 1). When compared to the mean baseline \pm SD size $\left(19.6 \pm 0 \mathrm{~cm}^{2}\right)$, retraction was the most important with FCS $5 \%\left(11.77 \pm 0.28 \mathrm{~cm}^{2}\right)$, GGO $76 \mathrm{mM}\left(13.99 \pm 27 \mathrm{~cm}^{2}\right)$, and GGO $252 \mathrm{mM}\left(13.79 \pm 0.24 \mathrm{~cm}^{2}\right)$.

Table I Fibroblast retraction kinetics of GGO

\begin{tabular}{llll}
\hline $\begin{array}{l}\text { Culture medium } \\
\text { containing }\end{array}$ & $\begin{array}{l}\text { Surface: mean } \pm \text { SD }\left(\mathbf{c m}^{2}\right) \\
\% \text { Retraction* }\end{array}$ \\
\cline { 2 - 4 } & \multicolumn{1}{l}{ Time } & \\
\cline { 2 - 4 } & $\pm \mathbf{~ h}$ & $\pm \mathbf{1 5} \mathbf{~ h}$ & $\pm 23 \mathbf{~}$ \\
\hline FCS I\% (negative control) & $19.6 \pm 0.0$ & $19.17 \pm 0.28$ & $18.17 \pm 0.07$ \\
& 0 & 2.04 & 7.14 \\
FCS 5\% (positive control) & $19.6 \pm 0.0$ & $14.94 \pm 0.49$ & $11.77 \pm 0.28$ \\
& 0 & 23.98 & 39.8 \\
GGO $8 \mu \mathrm{M}$ & $19.6 \pm 0.0$ & $18.4 \pm 0.19$ & $15.07 \pm 0.26$ \\
& 0 & 6.12 & 22.96 \\
GGO $25 \mu \mathrm{M}$ & $19.6 \pm 0.0$ & $17.8 \pm 0.22$ & $14.32 \pm 0.23$ \\
& 0 & 9.18 & 27.04 \\
GGO $76 \mu \mathrm{M}$ & $19.6 \pm 0.0$ & $17.42 \pm 0.14$ & $13.99 \pm 0.27$ \\
& 0 & 11.22 & 28.57 \\
GGO $252 \mu \mathrm{M}$ & $19.6 \pm 0.0$ & $16.62 \pm 0.32$ & $13.79 \pm 0.24$ \\
& 0 & 15.31 & 29.59 \\
\hline
\end{tabular}

Note: *Refers to the formula allowing for calculation of the percent retraction. Abbreviations: GGO, glycylglycine oleamide; h, hours; FCS, fetal calf serum.

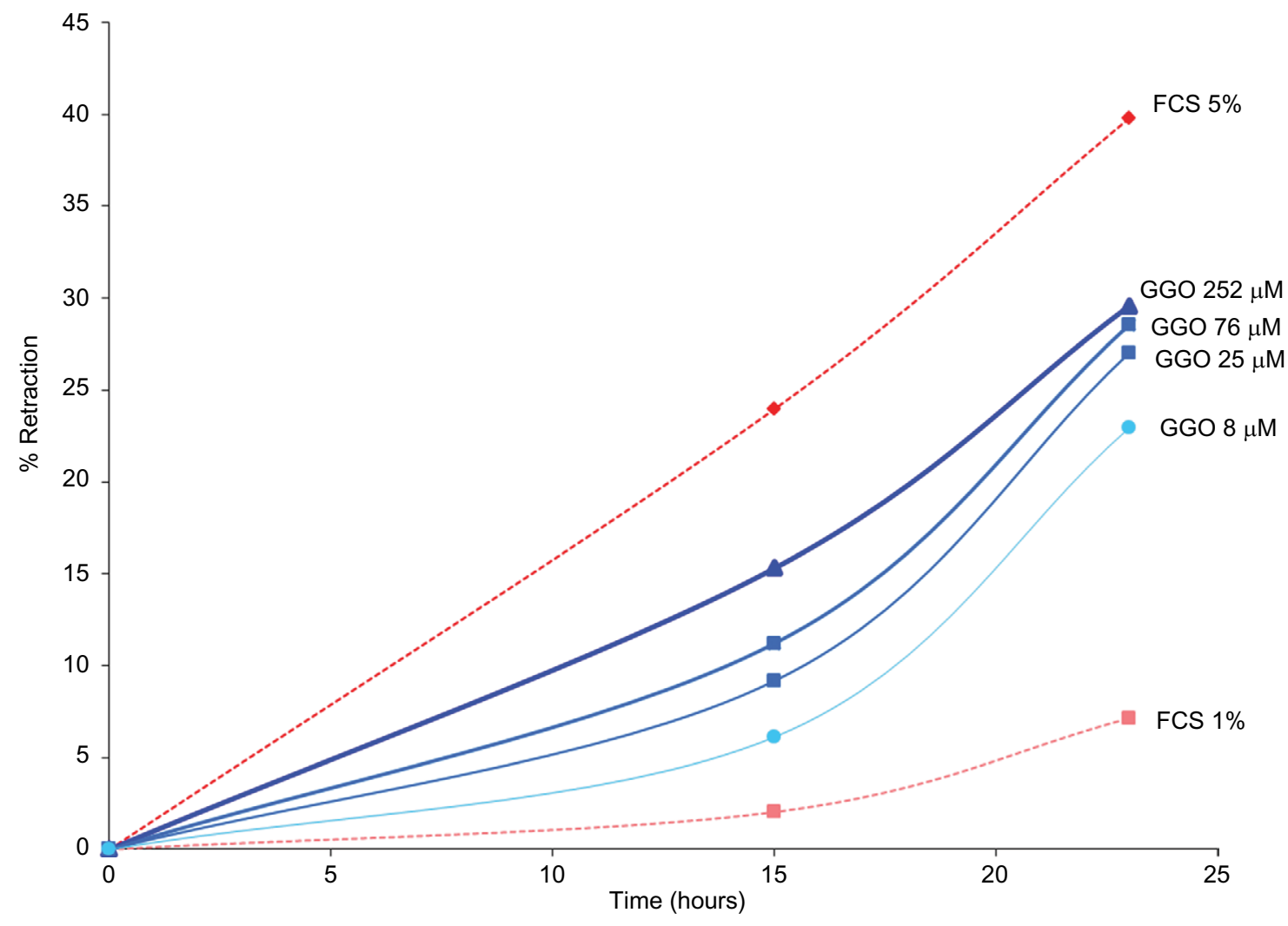

Figure 3 Collagen retraction assay assessing fibroblast contractility.

Notes: Retraction of fibroblasts obtained from human skin explants and treated with $8 \mu \mathrm{M}, 25 \mu \mathrm{M}, 76 \mu \mathrm{M}$, or $252 \mu \mathrm{M}$ GGO was assessed in percent up to 23 hours after beginning of the assay.

Abbreviations: GGO, glycylglycine oleamide; FCS, fetal calf serum. 


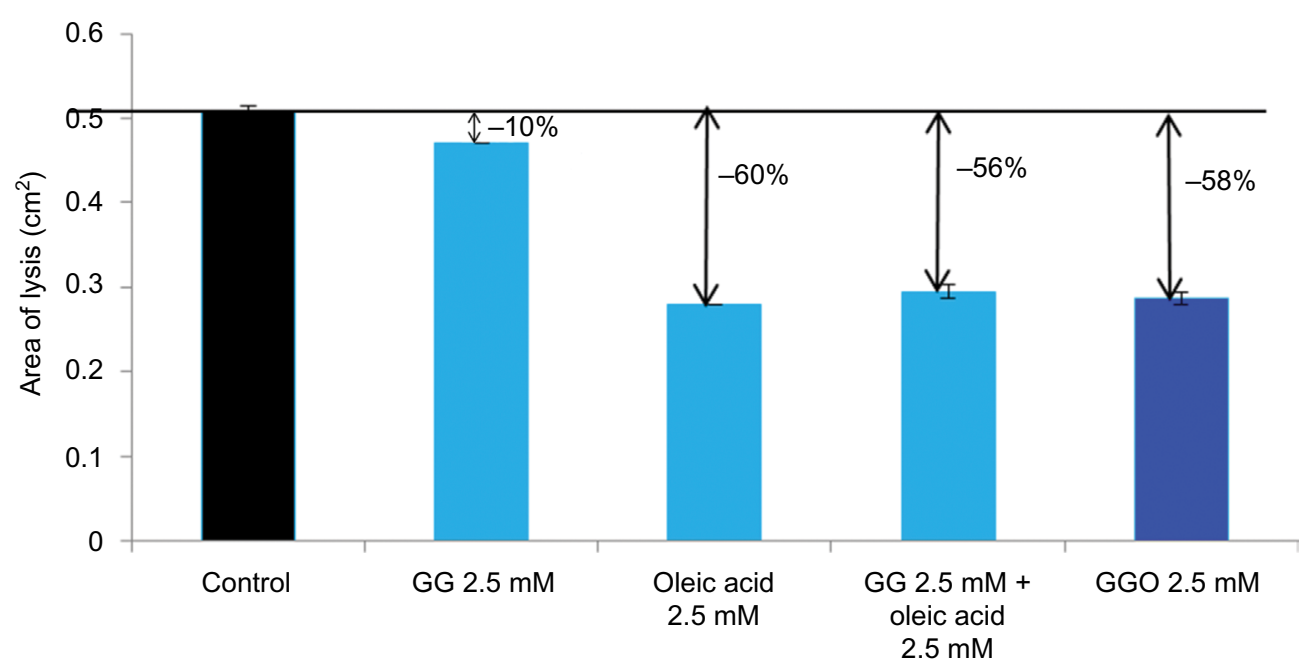

Figure 4 In vitro testing of the elastase (MMP-12) inhibiting potential of GGO.

Notes: The anti-elastase activity of GGO $2.5 \mathrm{mM}$ was compared to that of OA $2.5 \mathrm{mM}$, GG $2.5 \mathrm{mM}$, and a combination of OA $2.5 \mathrm{mM}$ and GG $2.5 \mathrm{mM}$ Abbreviation: MMP, matrix metalloproteinase; GGO, glycylglycine oleamide; OA, oleic acid; GG, glycylglycine.

\section{In vitro testing of the anti-elastase (MMP-I2) potential of GGO}

The anti-elastase activity of GGO $2.5 \mathrm{mM}$ was compared to that of OA $2.5 \mathrm{mM}, \mathrm{GG}$ at $2.5 \mathrm{mM}$, and a combination of OA $2.5 \mathrm{mM}$ and GG $2.5 \mathrm{mM}$ using an in vitro noncellular technique.

Results from this test confirmed that GGO $2.5 \mathrm{mM}$ inhibits MMP-12 activity by 58\%. In comparison, OA $2.5 \mathrm{mM}$ inhibited the activity of MMP-12 by $60 \%$, OA $2.5 \mathrm{mM}$ and GG $2.5 \mathrm{mM}$ by $56 \%$, and GG $2.5 \mathrm{mM}$ by $10 \%$ (Figure 4).

\section{Discussion}

The present in vitro and ex vivo studies focused on the architecture of the ECM fiber network and how the latter is protected from glycation when using different antiglycation agents. Results demonstrated that GGO reduced in vitro-induced glycation of type I collagen by almost $60 \%$. Furthermore, it restored the expression of fibrillin-1 inhibited by glycation and allowed for a tissue retraction of almost $50 \%$ in stimulating the metabolism of the fibroblasts. GGO stimulated the regenerative capacity of skin fibroblasts and inhibited MMP-12 by 58\% reaching almost the inhibition potential of the current standard control OA (60\%). Inhibition of MMP-12 is particularly important as it is partially responsible for the age-dependent fragmentation of the elastic fibers. ${ }^{29}$ Conversely, GG, which is well-known for its antiglycation potential, only inhibited MMP-12 by $10 \%$.

We acknowledge that our investigational approaches did not study cell-cell and cell-ECM signaling events or
ECM environment including its interaction with the basal membrane, processes that might contribute to the dermal fibroblast dysfunction observed in aging skin. ${ }^{30,31}$ Furthermore, the immunohistochemical approach we had chosen did not allow to clearly distinguish the expression of fibrillin-1 fibers from the eventuality of a modified antibody response to a change in the structure of the microfibrils. Another issue that may raise questioning resides in the choice of different concentrations of GGO. Therefore, the reason was the fact that, depending on the experiments, identical doses of GGO may be cytotoxic. Therefore, we adapted the chosen doses to the study design. We agree that this does not allow comparing the results obtained from the different experiments. Nevertheless, we showed in different studies that the GGO restores the collagen retraction potential, inhibits MMP-12, and restores the immunofluorescence signal.

\section{Conclusion}

The present studies support the claim that GGO, by interfering with the glycation process, potentially protects different components of the dermal ECM from breakdown and disorganization as shown in Figure 5. A model of UV-irradiated skin explants is currently developed to investigate how topical application of GGO prevents UV-induced dermal modifications. Other studies are needed to confirm the validity of these study results.

\section{Acknowledgment}

The authors acknowledge the writing support of Patrick Göritz, SMWS-Scientific and Medical Writing Services, France. 


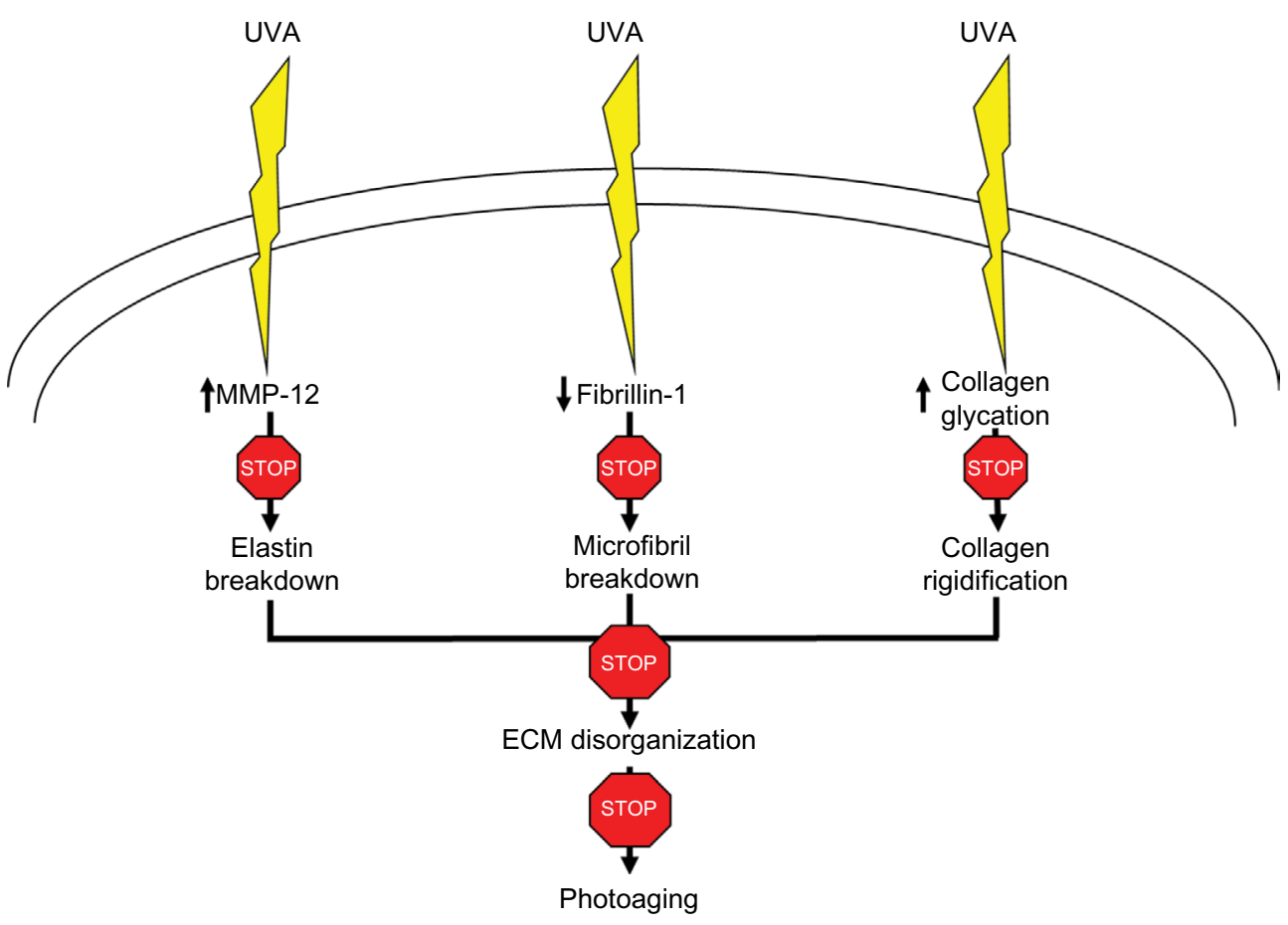

Figure 5 Mechanism of action of GGO on MMP-12, fibrillin-I, and collagen glycation after exposure to UVA light.

Abbreviations: GGO, glycylglycine oleamide; MMP, matrix metalloproteinase; ECM, extracellular matrix; UV, ultraviolet A.

\section{Disclosure}

The authors are employees of Pierre Fabre Dermo-Cosmétique, France. The authors report no other conflicts of interest in this work.

\section{References}

1. Watson RE, Ogden S, Cotterell LF, et al. Effects of a cosmetic 'antiageing' product improves photoaged skin [corrected]. $\mathrm{Br} J$ Dermatol. 2009;161(2):419-426.

2. Herman J, Rost-Roszkowska M, Skotnicka-Graca U. Skin care during the menopause period: noninvasive procedures of beauty studies. Postepy Dermatol Alergol. 2013;30(6):388-395.

3. Chung JH, Seo JY, Choi HR, et al. Modulation of skin collagen metabolism in aged and photoaged human skin in vivo. J Invest Dermatol. 2001;117(5):1218-1224.

4. Sorrell JM, Caplan AI. Fibroblast heterogeneity: more than skin deep. J Cell Sci. 2004;117(pt 5):667-675.

5. Werner S, Smola H. Paracrine regulation of keratinocyte proliferation and differentiation. Trends Cell Biol. 2001;11(4):143-146.

6. Detmar M. Molecular regulation of angiogenesis in the skin. $J$ Invest Dermatol. 1996;106(2):207-208.

7. Ansel JC, Kaynard AH, Armstrong CA, Olerud J, Bunnett N, Payan D. Skin-nervous system interactions. J Invest Dermatol. 1996;106(1): 198-204.

8. Metcalfe AD, Ferguson MW. Tissue engineering of replacement skin: the crossroads of biomaterials, wound healing, embryonic development, stem cells and regeneration. JR Soc Interface. 2007;4(14): 413-437.

9. Watt FM, Fujiwara H. Cell-extracellular matrix interactions in normal and diseased skin. Cold Spring Harb Perspect Biol. 2011;3(4):a005124.

10. Kielty CM, Woolley DE, Whittaker SP, Shuttleworth CA. Catabolism of intact fibrillin microfibrils by neutrophil elastase, chymotrypsin and trypsin. FEBS Lett. 1994;351(1):85-89.
11. Ashworth JL, Kelly V, Rock MJ, Shuttleworth CA, Kielty CM. Regulation of fibrillin carboxy-terminal furin processing by $\mathrm{N}$-glycosylation, and association of amino- and carboxy-terminal sequences. $J$ Cell Sci. 1999;112(pt 22):4163-4171.

12. Watson RE, Griffiths CE, Craven NM, Shuttleworth CA, Kielty CM. Fibrillin-rich microfibrils are reduced in photoaged skin. Distribution at the dermal-epidermal junction. $J$ Invest Dermatol. 1999;112(5):782-787.

13. Kligman AM. Early destructive effect of sunlight on human skin. JAMA. 1969;210(13):2377-2380.

14. Kligman AM. The treatment of photoaged human skin by topical tretinoin. Drugs. 1989;38(1):1-8.

15. Naylor EC, Watson RE, Sherratt MJ. Molecular aspects of skin ageing Maturitas. 2011;69(3):249-256.

16. Gasser P, Arnold F, Peno-Mazzarino L, et al. Glycation induction and antiglycation activity of skin care ingredients on living human skin explants. Int J Cosmet Sci. 2011;33(4):366-370.

17. DeGroot J. The AGE of the matrix: chemistry, consequence and cure Curr Opin Pharmacol. 2004;4(3):301-305.

18. Avery NC, Bailey AJ. The effects of the Maillard reaction on the physical properties and cell interactions of collagen. Pathol Biol (Paris). 2006;54(7):387-395.

19. Pageon H, Techer MP, Asselineau D. Reconstructed skin modified by glycation of the dermal equivalent as a model for skin aging and its potential use to evaluate anti-glycation molecules. Exp Gerontol. 2008;43(6):584-588.

20. Corstjens H, Dicanio D, Muizzuddin N, et al. Glycation associated skin autofluorescence and skin elasticity are related to chronological age and body mass index of healthy subjects. Exp Gerontol. 2008;43(7):663-667.

21. Verzij1 N, DeGroot J, Thorpe SR, et al. Effect of collagen turnover on the accumulation of advanced glycation end products. $J$ Biol Chem. 2000;275(50):39027-39031.

22. Farris PK. Innovative cosmeceuticals: sirtuin activators and antiglycation compounds. Semin Cutan Med Surg. 2011;30(3):163-166. 
23. Aguilar-Hernandez M, Mendez JD. In vitro glycation of brain aminophospholipids by acetoacetate and its inhibition by urea. Biomed Pharmacother. 2007;61(10):693-697.

24. Boldyrev AA, Aldini G, Derave W. Physiology and pathophysiology of carnosine. Physiol Rev. 2013;93(4):1803-1845.

25. Choudhary MI, Abbas G, Ali S, et al. Substituted benzenediol Schiff bases as promising new anti-glycation agents. J Enzyme Inhib Med Chem. 2011;26(1):98-103.

26. Brownlee M, Vlassara H, Kooney A, Ulrich P, Cerami A. Aminoguanidine prevents diabetes-induced arterial wall protein cross-linking. Science. 1986;232(4758):1629-1632.

27. Bell E, Ivarsson B, Merrill C. Production of a tissue-like structure by contraction of collagen lattices by human fibroblasts of different proliferative potential in vitro. Proc Natl Acad Sci US A. 1979;76(3): $1274-1278$.
28. Ashe BM, Zimmerman M. Specific inhibition of human granulocyte elastase by cis-unsaturated fatty acids and activation by the corresponding alcohols. Biochem Biophys Res Commun. 1977;75(1):194-199.

29. Robert L, Molinari J, Ravelojaona V, Andres E, Robert AM. Age- and passage-dependent upregulation of fibroblast elastase-type endopeptidase activity. Role of advanced glycation endproducts, inhibition by fucose- and rhamnose-rich oligosaccharides. Arch Gerontol Geriatr. 2010;50(3):327-331.

30. Okano Y, Masaki H, Sakurai H. Dysfunction of dermal fibroblasts induced by advanced glycation end-products (AGEs) and the contribution of a nonspecific interaction with cell membrane and AGEs. J Dermatol Sci. 2002;29(3):171-180.

31. Pageon $H$. Reaction of glycation and human skin: the effects on the skin and its components, reconstructed skin as a model. Pathol Biol (Paris). 2010; 58(3):226-231.
Clinical, Cosmetic and Investigational Dermatology

\section{Publish your work in this journal}

Clinical, Cosmetic and Investigational Dermatology is an international, peer-reviewed, open access, online journal that focuses on the latest clinical and experimental research in all aspects of skin disease and cosmetic interventions. This journal is included on PubMed. The manuscript management system is completely online
Dovepress

and includes a very quick and fair peer-review system, which is all easy to use. Visit http://www.dovepress.com/testimonials.php to read real quotes from published authors 